\title{
Uso Associado e Contribuições Relativas de Genótipos de Aveia e de Práticas de Manejo à Competitividade da Cultura com Plantas Concorrentes ${ }^{1}$
}

\author{
Associated Use and Relative Contributions of at Genotypes and Management Practices to Crop \\ Competitivity against Concurrent Plants
}

\author{
SCHAEDLER, C.E. ${ }^{2}$, FLECK, N.G. ${ }^{3}$, AGOSTINETTO, D. ${ }^{3}$, RIGOLI, R.P. ${ }^{4}$, DAL MAGRO, T. ${ }^{5}$ e \\ TIRONI, S.P. ${ }^{6}$
}

\begin{abstract}
RESUMO - A associação de práticas de manejo, como niveis populacionais e formas de aplicação de adubo nitrogenado, pode potencializar a habilidade competitiva de uma cultura com plantas concorrentes. O objetivo deste trabalho foi estabelecer as contribuições relativas de genótipos de aveia e de práticas de manejo, e seu uso associado, em influenciar a competitividade do cereal sobre plantas concorrentes. Para isso, foi conduzido um experimento em campo na Universidade Federal de Pelotas, em Capão do Leão-RS, durante a estação fria de 2006. O delineamento experimental utilizado foi o de blocos casualizados, com quatro repetições, em esquema fatorial $2 \times 2 \times 2 \times 2$ [condições de competição (ausência de plantas concorrentes e presença de linho + trigo, como competidores); cultivares de aveia (ALBASUL e UPF 16); população de plantas de aveia (230 e 150 plantas $\mathrm{m}^{-2}$ ); e formas de adubação nitrogenada (10 kg de $\mathrm{N} \mathrm{ha}^{-1}$ na semeadura, $15 \mathrm{~kg} \mathrm{ha}^{-1}$ no estádio da quarta folha de aveia e $20 \mathrm{~kg} \mathrm{ha}^{-1}$ no da sétima folha totalmente expandida; na outra modalidade, o $\mathrm{N}$ foi usado a $20 \mathrm{~kg} \mathrm{ha}^{-1}$ na semeadura, $15 \mathrm{~kg} \mathrm{ha}^{-1}$ no estádio da quarta folha e $10 \mathrm{~kg} \mathrm{ha}^{-1}$ no da sétima folha)]. Adicionalmente, foi acrescentada testemunha comparativa, contendo apenas a associação de linho e de trigo. Avaliaram-se diversas características morfológicas em plantas de aveia no início do ciclo de desenvolvimento e outras características agronômicas ao final do ciclo do cereal e de seus competidores. O cultivar UPF 16 demonstrou maior potencial competitivo no início do ciclo de desenvolvimento do que o ALBASUL. Maior população de aveia e maior quantidade de adubo nitrogenado aplicada na semeadura favorecem o aumento da produtividade de grãos e incrementam o potencial competitivo da aveia, estimulando a supressão das espécies competidoras.
\end{abstract}

Palavras-chave: Avena sativa, plantas daninhas, competição, população de plantas, adubação nitrogenada.

\begin{abstract}
The association of management practices, such as population level and forms of nitrogen fertilizer application, may increase the competitive potential of a crop against concurrent plants. The aim of this study was to establish the relative contributions of oat genotypes and management practices and their combined use in modifying the competitivity of the oat plant against concurrent plants. Thus, a field experiment was conducted at the Universidade Federal de Pelotas, in Capão do Leão-RS, during the winter season of 2006, in a completely randomized block design, with four replicates, in a $2 \times 2 \times 2 \times 2$ factorial scheme. The competition conditions were (absence of concurrent plants or presence of association of flax + wheat as concurrent plants), oat cultivars (ALBASUL or UPF 16), oat population (230 or 150 plants $\mathrm{m}^{-2}$ ), and forms of nitrogen splitting were $\left(10 \mathrm{~kg}\right.$ of $\mathrm{N} \mathrm{ha}^{-1}$ at seeding time, $15 \mathrm{~kg}$ of $\mathrm{N} \mathrm{ha}^{-1}$ at the four leaf stage, and $20 \mathrm{~kg}$ of $N \mathrm{ha}^{-1}$ at the seven leaf stage, or, alternatively, 20,15, and $10 \mathrm{~kg}$ of $N \mathrm{ha}^{-1}$ at those same times) as the factors
\end{abstract}

Recebido para publicação em 20.12.2008 e na forma revisada em 11.12.2009.

2 Engō-Agrọ , Aluno do Programa de Pós-Graduação em Fitossanidade, Faculdade de Agronomia Eliseu Maciel da Universidade Federal de Pelotas - FAEM/UFPel, <caduschaedler@yahoo.com.br>; ${ }^{3}$ Engo-Agro ${ }^{\text {, }}$ Professor do Dep. de Fitossanidade, FAEM/ UFPel, Bolsista de Produtividade em Pesquisa do CNPq; ${ }^{4}$ Bióloga, Mestranda do Programa de Pós-Graduação em Fitossanidade, FAEM/UFPel; ${ }^{5}$ Eng-â-Agr ${ }^{\mathrm{a}}$, Doutoranda do Programa de Pós-Graduação em Fitossanidade, FAEM/UFPel; ${ }^{6}$ Aluno do Curso de Graduação em Agronomia, FAEM/UFPel. 
studied. Additionally, a comparative check was added comprising only the association flax + wheat. The morphological characteristics of the oat plants, as well as of their competitors were evaluated in the beginning of the development period and other traits at oat maturity. The oat cultivar UPF 16 showed a greater competitive potential, compared to ALBASUL, at the initial period of growth. .Larger oat plant population and increase of nitrogen application at seeding time favor oat grain yield increase as well as its competitive potential increase, stimulating the suppression of the concurrent species.

Keywords: Avena sativa, weeds, interference, competition, plant population, nitrogen application.

\section{INTRODUÇÃO}

Dos produtos agrícolas que provêm alimentação às populações humana e animal, a aveia-branca (Avena sativa) ocupa uma posição de crescente destaque e expansão em área de cultivo. A produção de aveia no Brasil originase, principalmente, das lavouras cultivadas nos Estados do Rio Grande do Sul (RS) e Paraná (PR); o primeiro contribui com $57 \%$, aproximadamente, do total de grãos de aveia produzidos no País. A produtividade média de aveia no RS cresceu nos últimos dez anos, atingindo $1,9 \mathrm{t} \mathrm{ha}^{-1}$ (Conab, 2008). Esse fato decorre, especialmente, da utilização de cultivares com alto potencial produtivo, do uso apropriado de insumos e da adoção de tecnologias modernas. Contudo, essa produtividade ainda está aquém daquela alcançada em áreas de pesquisa. Isso resulta, em parte, da presença de plantas daninhas, as quais causam prejuizos quantitativos e qualitativos à produção do cereal.

Para manejo de plantas daninhas em áreas cultivadas com aveia, além do método químico, pode-se integrar o cultural, que visa proporcionar incremento na habilidade competitiva da cultura em relação às plantas daninhas. Entre as práticas culturais, destaca-se a escolha de cultivares competitivos. Um conjunto de características morfológicas e fisiológicas de plantas pode definir a capacidade de um cultivar competir com plantas daninhas.

$\mathrm{O}$ nitrogênio $(\mathrm{N})$ é elemento essencial ao crescimento das plantas, pois está presente na composição das mais importantes biomoléculas, como ATP, NADH, NADPH, clorofila, proteínas e inúmeras enzimas (Harper, 1994). O $\mathrm{N}$ exerce forte influência no crescimento e no desenvolvimento de plantas de aveia em estádios iniciais (Mundstock \& Bredemeier, 2001).
Assim, a aplicação de adubo nitrogenado representa uma prática cultural indispensável nessa cultura, objetivando alcançar elevadas produtividades. Para Blackshaw et al. (2004), o uso estratégico de nutrientes, ao favorecer a cultura, também poderá estimular a supressão do crescimento das plantas daninhas.

A densidade de semeadura da cultura também influencia o crescimento das plantas daninhas. Em pesquisa realizada com trigo, por meio de uma ampla faixa de ambientes, o aumento da densidade de semeadura de 100 para 200 plantas $\mathrm{m}^{-2}$ diminuiu pela metade a matéria seca de azevém e reduziu a perda de produtividade de grãos do trigo de $23 \%$ para $17 \%$ (Lemerle et al., 2004). No mesmo sentido, em cevada, a matéria seca da parte aérea e a produtividade de grãos não foram afetadas pela presença de aveia-silvestre (Avena fatua) quando o cereal foi semeado em alta densidade; todavia, para baixa e média densidades de semeadura da cultura, a produtividade de cevada reduziu $25 \%$ por efeito da competição daquela infestante (Scursoni \& Satorre, 2005).

Em decorrência do que foi exposto, faz-se necessário estudar mais os métodos culturais de manejo, como forma de aplicação do adubo nitrogenado e adequação da população de plantas, de modo que esses favoreçam o desenvolvimento das plantas de aveia quando em competição com plantas concorrentes. Essas práticas podem conferir à cultura habilidade competitiva superior na utilização daquele nutriente e de outros recursos disponibilizados no meio, como água e radiação solar.

Nesse sentido, a hipótese preconizada para esta pesquisa é de que a integração de práticas de manejo, como incremento da população de plantas de aveia e adequação da adubação nitrogenada, potencializa a capacidade inerente 
de cultivares de aveia em competir com plantas concorrentes. Desse modo, o objetivo deste trabalho foi estabelecer as contribuições relativas de dois genótipos de aveia e de práticas de manejo, bem como o seu uso associado, em influenciar a competitividade do cereal sobre plantas concorrentes.

\section{MATERIAL E MÉTODOS}

Foi conduzido um experimento em campo durante a estação fria de 2006, no Centro Agropecuário da Palma (CAP) da Universidade Federal de Pelotas (UFPel), no município de Capão do Leão-RS, em Argissolo VermelhoAmarelo, textura franco-arenosa, pertencente à unidade de mapeamento Pelotas (Embrapa, 1999). As principais características físico-químicas do solo da área experimental, resultantes de análise laboratorial realizada 40 dias antes da instalação do experimento, foram: argila, 16\%; pH, 5,2 (em água); indice SMP, 6,5; MO, 1,7; P, $35 \mathrm{mg} \mathrm{L}^{-1} ; \mathrm{K}, 74 \mathrm{mg} \mathrm{L}^{-1}$; $\mathrm{Al}$, $0,1 \mathrm{cmol}_{c} \mathrm{~L}^{-1} ; \mathrm{Ca}, 2,5 \mathrm{cmol}_{\mathrm{c}} \mathrm{L}^{-1} ; \mathrm{Mg}, 0,8 \mathrm{cmol}_{\mathrm{c}} \mathrm{L}^{-1}$; e CTC efetiva, $4,5 \mathrm{cmol}_{c} \mathrm{~L}^{-1}$.

Para implantação do experimento, escolheram-se dois cultivares de aveia (ALBASUL e UPF 16), os quais foram usados como reagentes à concorrência da associação de trigo e linho, utilizados como simuladores de plantas daninhas das classes liliopsidas e magnoliopsidas, respectivamente. O critério para escolha daqueles genótipos baseou-se, especialmente, em diferenças entre características, como estatura de planta e potencial de cobertura do solo, a partir de resultados obtidos em experimento realizado em campo na estação anterior de crescimento. O cultivar de trigo utilizado como concorrente foi o Ônix, enquanto o linho não teve o genótipo identificado.

O delineamento experimental utilizado foi o de blocos casualizados com quatro repetições, sendo as parcelas subdivididas. O esquema fatorial foi $2 \times 2 \times 2 \times 2$, como fator principal; nas parcelas com aveia foram comparadas duas condições de competição (presença ou ausência de plantas concorrentes). Nas subparcelas, compararam-se os dois cultivares de aveia citados anteriormente. O terceiro fator incluiu duas populações de aveia (230 e 150 plantas $\mathrm{m}^{-2}$ ), enquanto o quarto fator comparou duas formas de adubação nitrogenada. Neste caso, numa das formas o adubo nitrogenado foi usado a $10 \mathrm{~kg}$ de $\mathrm{N} \mathrm{ha}^{-1}$ na semeadura, $15 \mathrm{~kg} \mathrm{ha}^{-1}$ no estádio da quarta folha de aveia e $20 \mathrm{~kg} \mathrm{ha}^{-1}$ no da sétima folha totalmente expandida; já na outra modalidade, o $\mathrm{N}$ foi usado a $20 \mathrm{~kg} \mathrm{ha}^{-1}$ na semeadura, $15 \mathrm{~kg} \mathrm{ha}^{-1}$ no estádio da quarta folha e $10 \mathrm{~kg} \mathrm{ha}{ }^{-1}$ no da sétima folha. As populações de trigo e de linho foram relativamente equivalentes: 120 plantas $\mathrm{m}^{-2}$, em média. Adicionalmente, foram acrescentados tratamentos comparativos (testemunhas), contendo apenas a associação de trigo e de linho, com três repetições. Cada unidade experimental, em sua subdivisão final, mediu $5,66 \mathrm{~m}^{2}(1,53 \times 3,7 \mathrm{~m})$, constando de nove fileiras de aveia com $3,7 \mathrm{~m}$ de comprimento e espaçadas de 0,17 m. A área útil disponivel para colheita foi de $2,72 \mathrm{~m}^{2}$ $(1,36 \times 2,0 \mathrm{~m})$.

A semeadura dos cultivares de aveia e das espécies competidoras ocorreu dia 29 de junho de 2006, utilizando-se semeadora tracionada por trator. O trigo foi semeado em 18 fileiras perpendiculares às de aveia, enquanto o linho foi semeado a lanço. A adubação foi realizada de modo a obter, inicialmente, $10 \mathrm{~kg}$ de $\mathrm{N} \mathrm{ha}^{-1}$ nas subparcelas. Nesse sentido, utilizaramse $167 \mathrm{~kg}$ de adubo ha' ${ }^{-1}$, formulação 6-14-12, correspondendo a $10 \mathrm{~kg} \mathrm{ha}^{-1}$ de N, 23 de $\mathrm{P}_{2} \mathrm{O}_{5}$ e 20 de $\mathrm{K}_{2} \mathrm{O}$, respectivamente. Para as subparcelas com tratamento de $20 \mathrm{~kg}$ de $\mathrm{N} \mathrm{ha}^{-1}$, foram adicionados mais $10 \mathrm{~kg}$ de $\mathrm{N} \mathrm{ha}^{-1}$ na forma de ureia.

As variáveis avaliadas nos cultivares de aveia foram as seguintes: comprimento e largura da primeira folha, indice de potencial competitivo, cobertura do solo, estatura de planta, matéria seca da parte aérea (MPAS), produtividade biológica aparente (PBA) e produtividade de grãos. Em linho e trigo, avaliou-se a produtividade de grãos.

O comprimento e a largura da primeira folha foram determinados aos 14 dias após a emergência (DAE) da aveia, em dez plantas por unidade experimental, escolhidas aleatoriamente. Para se obter uma medida do potencial competitivo dos cultivares de aveia estimado quando do surgimento do primeiro nó, adaptouse a escala proposta por Lemerle et al. (2001). Realizou-se a avaliação de forma visual, 
utilizando-se características de planta, como: estatura, vigor, largura e inclinação das folhas, afilhamento e cobertura do solo. Essa avaliação foi realizada por dois avaliadores, que atuaram de modo independente e atribuíram notas individuais, as quais foram, posteriormente, combinadas para obtenção das respectivas médias. Essa variável foi determinada apenas nas parcelas com ausência de plantas competidoras.

A cobertura foliar do solo pelo dossel dos cultivares foi avaliada aos 14, 28 e $42 \mathrm{DAE}$, por meio dos métodos visual e fotográfico. A avaliação visual foi realizada utilizando-se escala percentual, em que a nota zero correspondeu à ausência de cobertura do solo pelo dossel das plantas e a nota 100 significou cobertura completa do solo. A avaliação foi feita por dois avaliadores, que atuaram de modo independente e atribuiram notas individuais, as quais foram, posteriormente, combinadas para obtenção das respectivas médias. Para se proceder à avaliação fotográfica, foram usadas duas áreas de $0,25 \mathrm{~m}^{2}$ em cada unidade experimental. Com auxílio de programa computacional, as fotos foram digitalizadas, para permitir a diferenciação da folhagem das plantas em relação ao solo. Posteriormente, com auxílio do programa Sigma Scan, foi estimada a participação da área ocupada pela parte aérea das plantas em relação à área total amostrada.

Quanto à estatura das plantas, tomou-se a medida desde o nível do solo até o ápice delas, com o limbo foliar distendido, sendo a variável avaliada aos 14, 28 e 42 DAE. As matérias das partes aéreas secas dos cultivares de aveia e das plantas concorrentes foram determinadas aos 28 e 42 DAE. Para obtenção dessa variável, foram coletadas plantas em área de $0,15 \mathrm{~m}^{2}$ em cada subparcela, fora da área destinada à produtividade de grãos. Em seguida, as espécies foram separadas, quando crescidas juntas, sendo acondicionadas em sacos de papel, secas em estufa a $60{ }^{\circ} \mathrm{C}$ por 72 horas e então pesadas. Os resultados foram expressos em g por planta.

As plantas contidas em área de 0,35 $\mathrm{m}^{2}$ por unidade experimental destinaram-se à determinação da PBA, que compreendeu o somatório das matérias das partes aéreas secas das plantas. Por ocasião da colheita das panículas dos cultivares, realizada aos $132 \mathrm{DAE}$, determinou-se a produtividade de grãos em área útil de $2,72 \mathrm{~m}^{2}$, a qual englobou as sete fileiras centrais das subparcelas. Após pesagem dos grãos, determinou-se sua umidade, e as massas foram corrigidas para $13 \%$ de umidade. A variável foi expressa em $\mathrm{kg} \mathrm{ha}^{-1}$.

Os dados obtidos foram analisados quanto à homocedasticidade e, posteriormente, procedeu-se à análise de variância, por meio do teste F, adotando-se como limites de aceitação de significância $5 \%$ de probabilidade, tanto para efeitos individuais dos fatores como para efeitos de interação. Nas situações em que houve significância estatística, as médias dos tratamentos foram comparadas através do teste $t$, adotando-se o nivel de $5 \%$ de probabilidade. Em relação aos dados obtidos para a variável produtividade de grãos dos cultivares reagentes, também se calcularam perdas percentuais, relativamente às parcelas testemunhas (ausência das espécies concorrentes), de acordo com a equação a seguir:

$$
\mathrm{P}(\%)=\left(\mathrm{P}_{\mathrm{a}}-\mathrm{P}_{\mathrm{p}} / \mathrm{Pa}\right) \times 100
$$

em que: $\mathrm{P}_{\mathrm{a}}$ e $\mathrm{P}_{\mathrm{p}}=$ produtividades do cultivar de aveia na ausência e na presença de espécies simuladoras de plantas concorrentes, respectivamente. Já as médias dos tratamentos que envolviam apenas as associações das competidoras, na ausência de aveia, foram comparadas aplicando-se o teste t a $5 \%$ de probabilidade.

\section{RESULTADOS E DISCUSSÃO}

Não houve interações entre os fatores cutivares $\mathrm{x}$ condições de competição $\mathrm{x}$ populações de plantas $\mathrm{x}$ formas de adubação nitrogenada. Para as variáveis comprimento e largura da primeira folha, houve diferença significativa apenas para o comprimento aos $14 \mathrm{DAE}$, destacando-se com maior valor (+19\%) o cultivar UPF 16 (Tabela 1). Embora para largura de folha não tenha sido constatada diferença entre os cultivares, o produto das duas variáveis diferiu: o cultivar UPF 16 apresentou média superior $(+20 \%)$ à do ALBASUL. O potencial competitivo dos dois cultivares de aveia, aos $42 \mathrm{DAE}$, indicou superioridade do UPF 16 sobre o ALBASUL (Tabela 2). 
Tabela 1 - Comprimento (C), largura (L) e área da primeira folha, medidos em plantas de dois cultivares de aveia aos 14 dias após a emergência. Capão do Leão-RS, 2006

\begin{tabular}{|l|c|c|c|}
\hline Cultivar & $\begin{array}{c}\text { Comprimento } \\
(\mathrm{cm})\end{array}$ & $\begin{array}{c}\text { Largura } \\
(\mathrm{cm})\end{array}$ & $\mathrm{C} \times \mathrm{L} \times\left(\mathrm{cm}^{2}\right)$ \\
\hline ALBASUL & $8,9^{*}$ & $0,53^{\mathrm{ns}}$ & $4,72^{*}$ \\
\hline UPF 16 & 10,6 & 0,53 & 5,62 \\
\hline Média & 9,8 & 0,53 & 5,17 \\
\hline
\end{tabular}

* Significativo pelo teste $\mathrm{t}(\mathrm{p} \leq 0,05)$; médias comparadas nas colunas. ${ }^{n s}$ Não significativo pelo teste $F(p \leq 0,05)$.

Tabela 2 - Índice de potencial competitivo de dois cultivares de aveia, avaliado visualmente, aos 42 dias após a emergência. Capão do Leão-RS, 2006

\begin{tabular}{|l|c|}
\hline \multicolumn{1}{|c|}{ Cultivar de aveia } & Índice $^{1 /}$ \\
\hline ALBASUL & $2,4^{*}$ \\
\hline UPF 16 & 3,7 \\
\hline Média & 3,1 \\
\hline
\end{tabular}

1/ Segundo escala proposta por Lemerle et al. (2001). * Significativo pelo teste $\mathrm{t}(\mathrm{p} \leq 0,05)$.

Em trigo, cultivares competitivos que apresentam elevada tolerância à pressão das plantas daninhas e, dessa forma, mantêm produtividade elevada na presença destas constituem-se em opção de baixo custo para reduzir a dependência aos herbicidas do cereal (Lemerle et al., 2006). O cultivar de aveia UPF 16, nas condições em que foi realizada a pesquisa, revelou elevado potencial no manejo cultural e integrado de plantas daninhas.

Quanto à variável cobertura do solo, quando avaliada visualmente, houve interação significativa entre niveis populacionais e cultivares de aveia, aos 28 DAE (Tabela 3 ). Para os dois cultivares, as maiores médias ocorreram na maior população de plantas; entretanto, o cultivar UPF 16 se destacou com maiores valores, quando comparado ao ALBASUL, nos dois niveis populacionais. Para cobertura do solo avaliada pelo método fotográfico, houve efeito significativo da interação cultivares de aveia $\mathrm{x}$ formas de adubação nitrogenada (Tabela 4). O cultivar UPF 16 se destacou por apresentar maiores coberturas em ambas as formas de adubação, quando comparado com o ALBASUL. No entanto, considerando-se a forma que utilizou $20+15+10 \mathrm{~kg}$ de $\mathrm{N} \mathrm{ha}^{-1}$, a cobertura do solo proporcionada por plantas do cultivar UPF 16 superou a forma de adubação $10+15+20 \mathrm{~kg} \mathrm{ha}^{-1}$, diferença que não ocorreu para ALBASUL.

Aos 14, 28 e $42 \mathrm{DAE}$ da aveia e na précolheita, o UPF 16 superou em estatura o ALBASUL. Houve variação na estatura de plantas de aveia em resposta aos fatores testados nesta pesquisa (Tabela 5). Contudo, a interação de condições de competição $\mathrm{x}$ formas de adubação nitrogenada não exerceu efeito diferencial sobre a variável. Desse modo, os dados apresentados referem-se apenas às médias dos fatores individuais testados.

Tabela 3 - Cobertura do solo (\%) formada por plantas de cultivares de aveia, em função de níveis populacionais, avaliada visualmente aos 28 dias após a emergência. Capão do Leão-RS, 2006

\begin{tabular}{|l|c|c|c|}
\hline \multirow{2}{*}{ Cultivar } & \multicolumn{2}{|c|}{ População $\left(\right.$ plantas $\left.\mathrm{m}^{-2}\right)$} & \multirow{2}{*}{ Média } \\
\cline { 2 - 3 } & 230 & 150 & \\
\hline ALBASUL & $* 32^{+}$ & $25^{+}$ & 29 \\
\hline UPF 16 & $44^{*}$ & 30 & 37 \\
\hline Média & 38 & 28 & \\
\hline CV $(\%)$ & \multicolumn{2}{|c|}{11,2} & \\
\hline
\end{tabular}

* Significativo pelo teste $\mathrm{t}(\mathrm{p} \leq 0,05)$; médias comparadas nas linhas. ${ }^{+}$Significativo pelo teste $\mathrm{t}(\mathrm{p} \leq 0,05)$; médias comparadas nas colunas.

Tabela 4 - Cobertura do solo (\%) formada por plantas de dois cultivares de aveia, em função de formas de adubação nitrogenada, avaliada através de método fotográfico aos 28 dias após a emergência. Capão do Leão-RS, 2006

\begin{tabular}{|l|c|c|c|}
\hline \multirow{2}{*}{ Cultivar } & \multicolumn{2}{|c|}{$\begin{array}{c}\text { Adubação nitrogenada } \\
\left(\mathrm{kg} \mathrm{de} \mathrm{N} \mathrm{ha}^{-1}\right)\end{array}$} & \multirow{2}{*}{ Média } \\
\cline { 2 - 3 } & $10+15+20^{1 /}$ & $20+15+10$ & \\
\hline ALBASUL & $39^{+}$ & $40^{+}$ & 40 \\
\hline UPF 16 & $49^{*}$ & 57 & 53 \\
\hline Média & 44 & 49 & \\
\hline CV $(\%)$ & \multicolumn{2}{|c|}{11,3} & \\
\hline
\end{tabular}

1/ Quantidades de adubo nitrogenado aplicadas na semeadura e nos estádios da quarta e da sétima folha totalmente expandidas. * Significativo pelo teste $\mathrm{t}(\mathrm{p} \leq 0,05)$; médias comparadas nas linhas. ${ }^{+}$Significativo pelo teste $\mathrm{t}(\mathrm{p} \leq 0,05)$; médias comparadas nas colunas. 
Tabela 5 - Estatura (cm) de plantas de dois cultivares de aveia, avaliada aos 14, 28 e 42 dias após a emergência (DAE) e na maturação de colheita. Capão do Leão-RS, 2006

\begin{tabular}{|l|c|c|c|c|}
\hline \multicolumn{1}{|c|}{ Cultivar } & 14 DAE & 28 DAE & 42 DAE & Maturação \\
\hline ALBASUL & $15^{*}$ & $30^{*}$ & $39^{*}$ & $101^{*}$ \\
\hline UPF 16 & 17 & 33 & 41 & 116 \\
\hline Média & 16 & 32 & 40 & 109 \\
\hline
\end{tabular}

* Significativo pelo teste $\mathrm{t}(\mathrm{p} \leq 0,05)$; médias comparadas nas colunas.

Para estatura de planta avaliada na précolheita, ocorreu interação dos fatores formas de adubação nitrogenada e condições de competição (Tabela 6). A menor estatura correspondeu a plantas de aveia que cresceram sob presença de linho + trigo e cuja adubação correspondeu à aplicação de $10+15+20 \mathrm{~kg}$ de $\mathrm{N} \mathrm{ha}^{-1}$. Geralmente, maior estatura de planta aponta para maior habilidade competitiva. Foi demonstrado que cultivares altos de trigo possuíam maior vigor inicial do que os baixos e, provavelmente, ambas as características, estatura e vigor inicial superiores, conferiram a eles maior habilidade competitiva com azevém (Lemerle et al., 2001). Em acréscimo, para Agostinetto et al. (2004), a adubação nitrogenada, quando aplicada totalmente na semeadura ou seu fracionamento na semeadura e no início da diferenciação das panículas, aumentou o crescimento em estatura em plantas de cultivares de arroz.

Quanto à variável MPAS de plantas de aveia por área, os resultados estão relacionados nas Tabelas 7 e 8 . Houve diferenças significativas para efeitos isolados dos fatores cultivares, niveis populacionais e formas de adubação nitrogenada. O cultivar UPF 16 apresentou maior matéria seca $(+23 \%)$ do que o ALBASUL. A maior população de plantas dos cultivares e a forma de adubação nitrogenada $20+15+10 \mathrm{~kg}$ de $\mathrm{N} \mathrm{ha}^{-1}$ propiciaram maiores médias à variável (Tabela 7). A maior população de plantas de aveia forneceu matéria seca $59 \%$ maior do que a população reduzida.

Um fator que influencia o crescimento das plantas daninhas é a densidade de semeadura da cultura. Em trigo, a matéria da parte aérea seca das plantas daninhas foi reduzida em cerca de $23 \%$, enquanto a produtividade da cultura aumentou $14 \%$, quando a densidade do trigo foi incrementada (Olsen et al., 2005). As populações de plantas de aveia também influenciaram diversas características avaliadas. Assim, para MPAS (28 DAE), cobertura do solo (28 DAE) e produtividade de grãos, a população de 230 plantas $\mathrm{m}^{-2}$ superou a de 150 plantas.

$\mathrm{Na}$ avaliação da MPAS aos $42 \mathrm{DAE}$, constatou-se interação dos fatores cultivares de aveia, populações de plantas e formas de adubação nitrogenada (Tabela 8). Sob população média de 230 plantas de aveia $\mathrm{m}^{-2}$, a aplicação de $20+15+10 \mathrm{~kg}$ de $\mathrm{N} \mathrm{ha}^{-1}$ favoreceu a MPAS de plantas do cultivar UPF 16, em comparação ao uso de $10+15+20 \mathrm{~kg}$ de $\mathrm{N}$ - fato que não ocorreu quando a população de aveia sofreu redução para 150 plantas $\mathrm{m}^{-2}$. Já para o cultivar

Tabela 6 - Estatura média (cm) de plantas de dois cultivares de aveia, avaliada na maturação de colheita, em função de formas de adubação nitrogenada e de condições de competição. Capão do Leão-RS, 2006

\begin{tabular}{|l|c|c|}
\hline \multirow{2}{*}{$\begin{array}{c}\text { Adubação nitrogenada } \\
\left(\mathrm{kg} \mathrm{de} \mathrm{N} \mathrm{ha}^{-1}\right)\end{array}$} & \multicolumn{2}{|c|}{ Competidor (linho + trigo) } \\
\cline { 2 - 3 } & Ausente & Presente \\
\hline $10+15+20^{1 /}$ & $111^{*}$ & $104^{+}$ \\
\hline $20+15+10$ & 109 & 110 \\
\hline Médias & 110 & 107 \\
\hline CV $(\%)$ & \multicolumn{2}{|c|}{5,6} \\
\hline
\end{tabular}

1/ Quantidades de adubo nitrogenado aplicadas na semeadura e nos estádios da quarta e da sétima folha totalmente expandidas.

* Significativo pelo teste $\mathrm{t}(\mathrm{p} \leq 0,05)$; médias comparadas nas linhas. ${ }^{+}$Significativo pelo teste $\mathrm{t}(\mathrm{p} \leq 0,05)$; médias comparadas nas colunas.

Tabela 7 - Matéria da parte aérea seca $\left(\mathrm{g} \mathrm{m}^{-2}\right)$ de plantas de aveia, em função de cultivares, níveis populacionais e formas de adubação nitrogenada, avaliada aos 28 dias após a emergência. Capão do Leão-RS, 2006

\begin{tabular}{|c|c|c|c|c|c|c|}
\hline \multirow{2}{*}{ Cultivar } & \multicolumn{2}{|c|}{$\begin{array}{c}\text { População } \\
\left(\text { plantas }^{-2}\right)\end{array}$} & $\begin{array}{c}\text { Adubação nitrogenada } \\
\left(\mathrm{kg} \mathrm{de} \mathrm{h} \mathrm{ha}^{-1}\right)\end{array}$ \\
\cline { 2 - 7 } & ALBASUL & UPF 16 & 230 & 150 & $10+15+20^{\frac{1}{}}$ & $20+15+10$ \\
\hline & $39^{*}$ & 48 & $54^{*}$ & 34 & $41^{*}$ & 46 \\
\hline Média & \multicolumn{2}{|c|}{44} & \multicolumn{2}{|c|}{44} & \multicolumn{2}{c|}{44} \\
\hline
\end{tabular}

1/ Quantidades de adubo nitrogenado aplicadas na semeadura e nos estádios da quarta e da sétima folha totalmente expandidas.

* Significativo pelo teste $\mathrm{t}(\mathrm{p} \leq 0,05)$; médias comparadas dentro de cada fator. 
Tabela 8 - Matéria seca da parte aérea $\left(\mathrm{g} \mathrm{m}^{-2}\right)$ de plantas de aveia, avaliada aos 42 dias após a emergência, em função de cultivares, níveis populacionais e formas de adubação nitrogenada. Capão do Leão-RS, 2006

\begin{tabular}{|c|c|c|c|c|}
\hline \multirow{4}{*}{ Cultivar } & \multicolumn{4}{|c|}{ População (plantas $\mathrm{m}^{-2}$ ) } \\
\hline & \multicolumn{2}{|c|}{230} & \multicolumn{2}{|c|}{150} \\
\hline & \multicolumn{4}{|c|}{ Adubação nitrogenada $\left(\mathrm{kg} \mathrm{de} \mathrm{N} \mathrm{ha}^{-1}\right)$} \\
\hline & $10+15+20^{\frac{1}{\prime}}$ & $20+15+10$ & $10+15+20$ & $20+15+10$ \\
\hline ALBASUL & $\mathrm{A}^{2} 127 * \mathrm{a}$ & A $129^{\text {ns }}$ a & B 80 a & A $107 \mathrm{a}$ \\
\hline UPF 16 & B $109^{\text {ns }}$ a & A $137 * \mathrm{a}$ & A 88 a & A $88 \quad$ a \\
\hline Média & 118 & 133 & 84 & 98 \\
\hline $\mathrm{CV}(\%)$ & \multicolumn{4}{|c|}{11,6} \\
\hline
\end{tabular}

${ }^{1 /}$ Quantidades de adubo nitrogenado aplicadas na semeadura e nos estádios da quarta e da sétima folha totalmente expandidas. ${ }^{2 /}$ Médias antecedidas por letras maiúsculas distintas, comparadas nas linhas, dentro de cada nível populacional, ou sucedidas por letras minúsculas diferentes, comparadas nas colunas, dentro do mesmo fator, diferem pelo teste $\mathrm{t}(\mathrm{p} \leq 0,05)$. Médias seguidas por ${ }^{\mathrm{ns}}$ ou ${ }^{*}$ comparam formas de adubação nitrogenada, em diferentes níveis populacionais.

ALBASUL o comportamento foi inverso: ele também produziu mais MPAS de plantas com adubação de 20+15+10 $\mathrm{kg}$ de $\mathrm{N} \mathrm{ha}^{-1}$, mas sob população de 150 plantas de aveia $\mathrm{m}^{-2}$, diferença que não existiu quando sua população foi de 230 plantas (Tabela 8).

Adicionalmente, houve outros comportamentos diferenciais dos cultivares em função das populações de aveia e das formas de adubação (Tabela 8). Assim, ALBASUL produziu mais matéria seca sob população de 230 plantas $\mathrm{m}^{-2}$ do que a população de 150 plantas, quando o nivel de adubação foi $10+15+20 \mathrm{~kg}$ de $\mathrm{N} \mathrm{ha}^{-1}$. Contudo, não houve tal diferença quando foram aplicados $20+15+10 \mathrm{~kg}$ de N. No caso de UPF 16, as respostas diferiram das daquele cultivar: também houve maior produção de matéria da parte aérea seca na população de 230 plantas $\mathrm{m}^{-2}$ do que na de 150 plantas, mas apenas sob a forma de adubação $20+15+10 \mathrm{~kg}$ de $\mathrm{N} \mathrm{ha}^{-1}$ (Tabela 8). Uma prática de manejo importante adotada para cereais de estação fria, como no caso da aveia, é a utilização de adubação nitrogenada. $\mathrm{O}$ nitrogênio $(\mathrm{N})$ exerce forte influência no crescimento e no desenvolvimento de plantas de aveia em estádios iniciais (Mundstock \& Bredemeier, 2001). Assim, a aplicação de adubo nitrogenado representa uma prática cultural indispensável nesta cultura, objetivando alcançar elevadas produtividades.

O uso estratégico de nutrientes, ao favorecer a cultura, poderá estimular a supressão do crescimento das plantas daninhas
(Blackshaw et al., 2004). Entretanto, plantas daninhas em geral também respondem eficientemente a taxas elevadas de N. No caso da cultura do arroz, em competição com arrozvermelho, este produziu mais matéria seca sob niveis elevados de N (Burgos et al., 2006). Ainda, em arroz irrigado, trabalho demonstrou que o capim-arroz comprometeu a adubação nitrogenada realizada na cultura, alterando características como matéria seca da parte aérea, afilhamento e número e peso das panículas (Blanco et al., 1991). Neste trabalho, os prejuízos incrementaram de acordo com o aumento da população do capim-arroz.

Em relação à PBA dos cultivares de aveia, constatou-se diferença significativa entre as duas condições de competição, ocorrendo redução média de $19 \%$ na variável em decorrência da competição exercida pela associação dos competidores linho+trigo. Entretanto, comparação entre os cultivares indicou que UPF 16 apresentou maior PBA do que ALBASUL, com diferença entre ambos de $12 \%$ (dados não mostrados).

Os dados referentes às produtividades de grãos - médias de dois cultivares de aveia - são apresentados na Tabela 9, com base nos niveis populacionais e condições de competição avaliados. $O$ teste $t$ indicou diferenças para cada um dos fatores investigados. Ocorreu maior produtividade no nivel mais elevado de plantas de aveia, o qual superou em $10 \%$ o nível populacional mais baixo. A condição de ausência de espécies concorrentes (linho + trigo) 
propiciou produtividade de grãos $22 \%$ maior do que na presença de competidores (Tabela 9).

As produtividades de grãos combinadas e, também, separadas das espécies concorrentes linho e trigo, quando associadas ou não aos cultivares de aveia, encontram-se relacionadas na Tabela 10. A associação dos competidores linho + trigo à aveia originou produtividade combinada $36 \%$ superior quando cresceram em presença do cultivar de aveia ALBASUL, comparativamente a UPF 16 . Isso denota que este exerceu efeito competitivo maior do que o primeiro cultivar sobre as espécies concorrentes. De qualquer forma, em comparação à ausência de aveia (testemunha), os cultivares deste cereal reduziram a produtividade de grãos combinada das espécies concorrentes em $79 \%$, aproximadamente. Por outro lado, a contribuição individual do trigo à produtividade de grãos combinada foi muito superior à do linho (13,4 e 15,6 vezes maior, dependendo do cultivar de aveia). Contudo, onde aveia esteve ausente (testemunha), a contribuição relativa do trigo para a produtividade global da associação reduziu para 7,5 vezes a do linho cerca de metade da relação encontrada na condição de presença de aveia. Isso mostra que o linho foi muito suscetivel à competição da aveia.

Os cultivares de aveia testados neste experimento responderam de forma diferenciada às práticas de manejo e à competitividade das espécies concorrentes linho e trigo (associados). Os resultados demonstraram que o cultivar UPF 16 foi o genótipo que se mostrou mais promissor, do ponto de vista de potencial competitivo inicial. A comparação entre ambos os cultivares de aveia revelou que UPF 16 superou ALBASUL em comprimento e área da primeira folha, indice de potencial competitivo, estatura de planta (todas as avaliações), matéria da parte aérea seca (28 DAE) e cobertura do solo (28 DAE).

Para formas de adubação nitrogenada, verificaram-se efeitos superiores da antecipação da maior fração de $\mathrm{N}\left(20+15+10 \mathrm{~kg} \mathrm{ha}^{-1}\right)$ para a variável MPAS desta (28 DAE). Em relação à matéria seca de aveia aos $42 \mathrm{DAE}$, houve respostas diferenciadas à adubação nitrogenada, conforme o cultivar e a população de plantas. Assim, para ambos os cultivares, verificaram-se maiores valores para matéria
Tabela 9 - Produtividades de grãos $\left(\mathrm{kg} \mathrm{ha}^{-1}\right)$, médias de dois cultivares de aveia, em função de níveis populacionais e de condições de competição. Capão do Leão-RS, 2006

\begin{tabular}{|c|c|c|c|c|}
\hline \multirow{2}{*}{} & \multicolumn{2}{|c|}{ População (plantas $\mathrm{m}^{-2}$ ) } & \multicolumn{2}{c|}{ Competidor (linho + trigo) } \\
\cline { 2 - 5 } & 230 & 150 & Ausentes & Presentes \\
\hline & $4.801^{*}$ & 4.321 & $5.051^{*}$ & 3.978 \\
\hline Média & \multicolumn{2}{|c|}{4561} & \multicolumn{2}{c|}{4515} \\
\hline
\end{tabular}

* Significativo pelo teste $\mathrm{t}(\mathrm{p} \leq 0,05)$; médias comparadas dentro de cada fator.

Tabela 10 - Produtividades médias de grãos de linho e de trigo quando associados ou não a dois cultivares de aveia. Capão do Leão-RS, 2006

\begin{tabular}{|l|c|c|c|}
\hline \multirow{2}{*}{ Cultivar associado } & \multicolumn{3}{|c|}{ Produtividade $\left(\mathrm{kg} \mathrm{ha}^{-1}\right)$} \\
\cline { 2 - 4 } & Linho & Trigo & $\begin{array}{c}\text { linho }+ \\
\text { trigo }\end{array}$ \\
\hline ALBASUL & $71^{*}$ & $949^{*}$ & $1.020^{*}$ \\
\hline UPF 16 & 45 & 703 & 748 \\
\hline Competidor solteiro (testemunha) & 417 & 3.141 & 3.558 \\
\hline
\end{tabular}

* Significativo pelo teste $\mathrm{t}(\mathrm{p} \leq 0,05)$; médias comparadas nas colunas.

seca quando o $\mathrm{N}$ foi aplicado na forma 20+ $15+10 \mathrm{~kg}$; no entanto, para UPF 16 esse efeito ocorreu sob população de 230 plantas, enquanto para ALBASUL ele se deu na menor população de aveia (150 plantas $\mathrm{m}^{-2}$ ). Igualmente, para cobertura do solo aos 28 DAE, o cultivar UPF 16 foi beneficiado por aquela forma de adubação. Para estatura de planta de aveia na maturação, sob efeito da presença de plantas concorrentes, a forma de adubação nitrogenada $20+15+10 \mathrm{~kg}$ também propiciou maior valor à variável.

A presença de plantas concorrentes (linho + trigo) alterou a produtividade dos cultivares de aveia, causando-lhes redução média da ordem de $21 \%$, em decorrência da competição exercida durante todo o ciclo da aveia. Por outro lado, constatou-se que a presença de aveia reduziu a produtividade das competidoras linho + trigo; contudo, tal resposta foi mais acentuada em presença do cultivar UPF 16 do que de ALBASUL.

Niveis populacionais elevados da cultura favorecem o aumento da produtividade e do potencial competitivo da aveia. Também, o adubo nitrogenado aplicado em maior quantidade na semeadura favorece os cultivares de 
aveia, estimulando a supressão das espécies competidoras. Enfatiza-se que os resultados obtidos nesta pesquisa devem ser considerados com alguma cautela devido às interações significativas dos efeitos de cultivares $\mathrm{x}$ locais $\mathrm{x}$ anos. Desse modo, recomenda-se conduzir pesquisas utilizando maior número de genótipos, em diferentes locais e anos.

Ocorreu maior potencial competitivo no início do ciclo de desenvolvimento no cultivar UPF 16, enquanto o cultivar ALBASUL demonstrou baixa capacidade competitiva nesta fase. A combinação de práticas de manejo, como aumento da população de plantas e incremento no uso de nitrogênio na semeadura, potencializa a habilidade competitiva da aveia com plantas concorrentes para o cultivar UPF 16. Contudo, resultado semelhante não foi observado para o cultivar ALBASUL, demonstrando que a associação com as práticas de manejo favorece o potencial competitivo do cereal com plantas daninhas, mas isso irá depender do cultivar em questão. Plantas de cultivares de aveia se beneficiam de maior nivel populacional, elevando estatura, matéria da parte aérea seca e produtividade de grãos.

\section{LITERATURA CITADA}

AGOSTINETTO, D. et al. Influência de cultivares de arroz e épocas de adubação nitrogenada nas relações de interferência da cultura com cultivar simulador de infestação de arrozvermelho. Planta Daninha, v. 22, n. 2, p. 185-193, 2004.

BLACKSHAW, R. E; MOLNAR, L. J.; JANZEN, H. H. Nitrogen fertilizer timing and application method affect weed growth and competition with spring wheat. Weed Sci., v. 52, n. 4, p. 614-622, 2004.

BLANCO, H. G. et al. Efeito da convivência de Echinochloa crus-galli (L.) Beauv. (capim-arroz) com plantas de arroz em diferentes níveis de nitrogênio e fósforo. Pesq. Agropec.

Bras., v. 26, n. 2, p. 193-199, 1991
BURGOS, N. R. et al. Competitive N uptake between rice and weedy rice. Field Crops Res., v. 99, n. 2-3, p. 96-105, 2006.

CONAB. Aveia: Comparativo de área, produção e produtividade. Safras 2007/08. Disponível em: $<$ http://www.conab.gov.br>. Acesso em: 30 de out. de 2008.

EMPRESA BRASILEIRA DE PESQUISA AGROPECUÁRIA - EMBRAPA. Centro Nacional de Pesquisa de Solos. Sistema brasileiro de classificação de solos. Brasília: 1999. 412 p.

HARPER, J. E. Nitrogen metabolism. In: BOOTE, K. J. et al. Physiology and determination of crop yield. Madison: ASA/CSSA/SSSA, 1994. p. 285-302.

LEMERLE, D. et al. Genetic improvement and agronomy for enhanced wheat competitiveness with weeds. Austr. J. Agric. Res., v. 52, n. 5, p. 527-548, 2001.

LEMERLE, D. et al. Reliability of higher seeding rates of wheat for increased competitiveness with weeds in low rainfall environments. J. Agric. Sci., v. 142, n. 1, p. 395-409, 2004.

LEMERLE, D. et al. Incremental crop tolerance to weeds: A measure for selecting competitive ability in Australian wheats Euphytica, v. 149, n. 1-2, p. 85-95, 2006.

MUNDSTOCK, C. M.; BREDEMEIER, C. Disponibilidade de nitrogênio e sua relação com o afilhamento e o rendimento de grãos de aveia. Ci. Rural, v. 31, n. 2, p. 205-211, 2001.

OLSEN, J.; KRISTENSEN, L.; WEINER, J. Effects of density and spatial pattern of winter wheat on suppression of different weed species. Weed Sci., v. 53, n. 5, p. 690-694, 2005.

SCURSONI, J. A.; SATORRE, E. H. Barley (Hordeum vulgare) and wild oat (Avena fatua) competition is affected by crop and weed density. Weed Technol., v. 19, n. 4, p. 790-795, 2005. 